\title{
Repair Capacity for Platinum-DNA Adducts Determines the Severity of Cisplatin-Induced Peripheral Neuropathy
}

\author{
Anna Dzagnidze, ${ }^{1}$ Zaza Katsarava, ${ }^{2}$ Julia Makhalova, ${ }^{1}$ Bernd Liedert, ${ }^{1}$ Min-Suk Yoon, ${ }^{2}$ Holger Kaube, ${ }^{3,4}$ \\ Volker Limmroth, ${ }^{2}$ and Juergen Thomale ${ }^{1}$ \\ ${ }^{1}$ Institut für Zellbiologie (Tumorforschung) and ${ }^{2}$ Klinik für Neurologie, Universitätsklinikum der Universität Duisburg-Essen, D-45122 Essen, Germany, \\ ${ }^{3}$ Department of Neurology and Neurophysiology, University of Freiburg, D-79095 Freiburg, Germany, and 4Division of Neurosciences, Medical School, \\ Southampton University, Southampton S016 64D, United Kingdom
}

\begin{abstract}
The pronounced neurotoxicity of the potent antitumor drug cisplatin frequently results in the onset of peripheral polyneuropathy (PNP), which is assumed to be initially triggered by platination products in the nuclear DNA of affected tissues. To further elucidate the molecular mechanisms, we analyzed in a mouse model the formation and processing of the main cisplatin-induced DNA adduct (guanine- guanine intrastrand cross-link) in distinct neuronal cell types by adduct-specific monoclonal antibodies. Comparison of the adduct kinetics in cisplatin-injected mice either proficient or deficient for nucleotide excision repair (NER) functions revealed the essential role of this DNA repair pathway in protecting differentiated cells of the nervous system from excessive formation of such lesions. Hence, chronic exposure to cisplatin resulted in an accelerated accumulation of unrepaired intrastrand cross-links in neuronal cells of mice with dysfunctional NER. The augmented adduct levels in dorsal root ganglion (DRG) cells of those animals coincided with an earlier onset of PNP-like functional disturbance of their sensory nervous system. Independently from the respective repair phenotype, the amount of persisting DNA cross-links in DRG neurons at a given cumulative dose was significantly correlated to the degree of sensory impairment as measured by electroneurography. Collectively, these findings suggest a new model for the processing of cisplatin adducts in primary neuronal cells and accentuate the crucial role of effectual DNA repair capacity in the target cells for the individual risk of therapy-induced PNP.
\end{abstract}

Key words: DNA adducts; repair; cisplatin; polyneuropathy; monoclonal antibodies; dorsal root ganglion

\author{
Introduction \\ Cisplatin (cis-diamminedichloroplatinum) is a widely used and \\ effective anticancer drug. Treatment, however, is associated with \\ several side effects such as nephrotoxicity and neurotoxicity \\ (Mollman, 1990). Although damage of kidney tubular epithe- \\ lium cells can be avoided by forced diuresis, peripheral neurotox- \\ icity remains a severe clinical problem and a major dose-limiting \\ factor of cisplatin therapy (LoMonaco et al., 1992). Patients with \\ cisplatin-induced polyneuropathy (PNP) typically present distal \\ paraesthesiae, and loss of joint position and vibration sense, re- \\ sulting in sensory ataxia (Hansen et al., 1989). Electrophysiolog- \\ ical investigations reveal a decrease or absence of sensory nerve \\ conduction potentials, decrease of sensory nerve conduction ve- \\ locities, and a delay or absence of H-reflex responses (Krarup- \\ Hansen et al., 1993). Sural nerve biopsies show degeneration of \\ large myelinated axons with signs of segmental demyelination

\footnotetext{
Received Feb. 6, 2007; revised June 26, 2007; accepted July 5, 2007.

This work was supported in part by Deutsche Forschungsgemeinschaft Grant FG 236 TP 1a (J.T.) and a grant of the Medical Faculty, University Duisburg-Essen (IFORES Program) (V.L., J.T.). We thank Dr. Kiyoji Tanaka (University of Osaka, Osaka, Japan) and Dr. Leon Mullenders (University of Leiden, Leiden, The Netherlands) for providing the XPA and XPC mice, respectively, and Beate Karow for expert technical assistance.

Correspondence should be addressed to Dr. Juergen Thomale, Institute of Cell Biology, Cancer Research, University of Duisburg-Essen Medical School, Hufelandstrasse 55, D-45122 Essen, Germany. E-mail: Juergen.thomale@uni-essen.de.

DOI:10.1523/JNEUROSCI.0523-07.2007

Copyright $\odot 2007$ Society for Neuroscience $\quad$ 0270-6474/07/279451-07\$15.00/0
}

and remyelination (Thompson et al., 1984). Motor fibers are usually unaffected.

The antineoplastic activity of cisplatin is based on the formation of platination products in the nuclear DNA (Boulikas and Vougiouka, 2003). Several of these adducts have been structurally identified, of which the guanine-guanine intrastrand cross-link cis- $\mathrm{Pt}\left(\mathrm{NH}_{3}\right)_{2} \mathrm{~d}(\mathrm{pGpG})[\mathrm{Pt}-(\mathrm{GG})]$ represents $>70 \%$ of total DNA platination. Persistence of these lesions in the nuclear DNA can lead to impaired replication and transcription and can trigger apoptotic processes (Siddik, 2003). Mammalian cells are equipped with several DNA repair mechanisms that counteract the deleterious effects of damaged DNA. Nucleotide excision repair (NER) has been suggested to be the main cellular defense mechanism against cisplatin-induced intrastrand cross-links (Furuta et al., 2002; Welsh et al., 2004). This complex pathway requires the cooperative action of more than a dozen factors including the xeroderma pigmentosum (XP) proteins A to $\mathrm{G}$ (Wood et al., 2000).

The precise mechanisms of cisplatin-induced peripheral neurotoxicity and the onset of PNP are still obscure. Although there is increasing evidence that the formation of DNA platination products in dorsal root ganglion (DRG) cells is the main trigger for the malfunction of the sensory nervous system (Meijer et al., 1999; McDonald and Windebank, 2002; Ta et al., 2006), the lack of appropriate analytical tools has hampered a more detailed un- 
derstanding of the molecular mechanisms and the identification of individual risk factors. To overcome this limitation, we established a novel sensitive method to visualize and quantify structurally defined cisplatin-DNA lesions in the nuclei of individual cells using adduct-specific monoclonal antibodies and quantitative image analysis (Liedert et al., 2006).

The aim of the current study was to test the hypothesis whether the levels of accumulated DNA platination products in dorsal root ganglion cells are causative for the functional impairment of peripheral nerve fibers in mice after the application of cisplatin. We, therefore, first measured the kinetics of formation and removal of Pt-(GG) adducts in various nervous tissue cells of three mouse strains differing in their capability to eliminate DNA damage via the NER pathway. Second, we investigated whether the differential DNA repair capacity of NER-proficient and -deficient mice determines the accumulation of Pt-DNA adducts after repetitive exposure to cisplatin and whether this, in turn, correlates with the severity of peripheral neuropathy.

\section{Materials and Methods}

Animals. C57BL/6 mice were used as DNA repair-competent wild-type (WT) mice throughout all experiments. Syngenic Xeroderma pigmentosum complementation group A (XPA)-deficient mice were a generous gift from Dr. K. Tanaka (University of Osaka, Osaka, Japan). Both strains were propagated by house breeding and $\mathrm{XPA}^{-1-}$ homozygocity was verified by PCR analysis (Nakane et al., 1995). Xeroderma pigmentosum complementation group C (XPC)-deficient mice (Berg et al., 1998) were kindly provided by Dr. L. Mullenders (Leiden University, Leiden, The Netherlands). Animals were housed under specific pathogen-free conditions with a $12 \mathrm{~h}$ light/dark cycle and allowed food and water ad libitum. All experiments were approved by the state animal welfare board.

Study design. For the detection and quantification of specific DNA platination products in nervous tissue cells and for the establishment of DNA repair kinetics, mice were injected with a single dose of cisplatin (2 or $10 \mathrm{mg} / \mathrm{kg}$ body weight, i.p.; Platinex, Bristol, München). Animals were killed at various time points between $6 \mathrm{~h}$ and $5 \mathrm{~d}$ after cisplatin administration. For the measurement of cisplatin-DNA adducts, dorsal root ganglia (lumbar) and lumbar enlargement of the spinal cord were removed on ice and frozen immediately in liquid $\mathrm{N}_{2}$.

In the second set of experiments male WT and XPA mice were exposed to repetitive applications of cisplatin. Starting at the age of 12 weeks, the animals were injected with $0.5 \mathrm{mg}$ of cisplatin/ $\mathrm{kg}$ body weight twice per week up to cumulative doses of $32 \mathrm{mg}$ (WT) or $8 \mathrm{mg}$ (XPA). To prevent renal damage, all mice were intraperitoneally injected with $1 \mathrm{ml}$ of saline solution immediately after each treatment. In all experiments, control animals were included which were injected with sterile saline.

Groups of 10 randomly selected mice were subjected to electrophysiological examination at the indicated cumulative doses and animals were killed immediately after the examination by supramaximal anesthesia with diethyl ether. Samples of neuronal tissues were removed and stored frozen as above.

Electrophysiological examination of motor and sensory nerve fibers. All electrophysiological examinations were performed under general anesthesia with phenobarbital (inactin, i.p., $50 \mathrm{mg} / \mathrm{kg}$ body weight; Sigma, St. Louis, MO). To minimize the influence of the body temperature on the nerve conduction, animals were placed on a water-heated glass plate maintaining the hind paw skin temperature at $37^{\circ} \mathrm{C}$.

Sensory- and motor-nerve conduction velocities were calculated using recordings of $\mathrm{H}$ - and $\mathrm{M}$-responses after stimulation of sciatic nerves as described previously (Verdu et al., 1999). Briefly, the sciatic/tibial nerves were stimulated percutaneously through a pair of monopolar needle electrodes placed at the sciatic notch and at the ankle. The ground electrode was placed at the base of the tail. Square-wave electrical pulses of 0.7 ms duration were delivered by Pulsemaster A 300 stimulator through an A 365 stimulus-isolation unit (World Precision Instruments, Sarasota, FL). The stimuli were applied starting from $0.1 \mathrm{~mA}$ up to $25 \%$ above the amperage that gave a maximal response.
The compound muscle action potentials elicited by orthodromic conduction (M-response) and by the monosynaptic reflex arc (H-response) were recorded from the fourth interosseous muscle of the hindfoot with a pair of microneedle recording electrodes. After amplification (INH four-channel differential amplifier; World Precision Instruments, Berlin, Germany), the evoked action potentials were sampled and analyzed by means of a CED micro1401 system with the Signal for Windows version 2.05 software (Cambridge Electronic Design, Cambridge, UK).

Peak-to-peak amplitudes of $\mathrm{M}$ - and $\mathrm{H}$-responses were measured. The response latencies (in milliseconds) were defined as the interval between the stimulus artifact and the beginning of the $\mathrm{M}$ - or $\mathrm{H}$-response. The distance between the two stimulation points was measured over the skin with the hip and knee in a flexed position. Motor-nerve (MNCV) and $\mathrm{H}$-reflex-related sensory-nerve conduction velocity (SNCV) were calculated as follows: $\mathrm{MNCV}, \mathrm{m} / \mathrm{s}=$ distance (sciatic notch to ankle)/latency (sciatic notch M-response - ankle M-response); $\mathrm{SNCV}, \mathrm{m} / \mathrm{s}=$ distance (sciatic notch to ankle)/latency (ankle H-response - sciatic notch H-response).

Mean values for each experimental group were calculated for amplitudes of $\mathrm{H}$ - and M-responses as well as for SNVC and MNCV.

Cell-type-specific measurement of cisplatin-induced DNA adducts. Frozen sections $(8 \mu \mathrm{m})$ were prepared from the collected tissue samples and were placed onto ImmunoSelect adhesion slides (Squarix Biotechnology, Marl, Germany) to prevent cell loss during additional processing. Twenty randomly selected sections of each tissue sample were analyzed by immunostaining.

Histological staining and cell type identification. To allow cell-typespecific quantification of DNA adducts neurons and glial or satellite cells were labeled by immunohistochemical staining. After fixation (methanol, $-20^{\circ} \mathrm{C}, 12 \mathrm{~h}$ ), oligodendrocytes and satellite cells were stained with anti-(CNPase) antibodies ( $5 \mu \mathrm{g} / \mathrm{ml}$ in PBS, $90 \mathrm{~min}, 37^{\circ} \mathrm{C}$; Sigma $)$ and secondary antibodies labeled with Alexa Fluor $488(5 \mu \mathrm{g} / \mathrm{ml}$ in $1 \%$ casein/ PBS; Invitrogen, Eugene, OR). Neurons were labeled with NeuroTrace 530/615 red fluorescent Nissl Stain (Invitrogen) according to the manufacturer's protocol. The nuclear DNA was counterstained with 4,6,diamidino-2-phenylindole (DAPI) $(1 \mu \mathrm{g} / \mathrm{ml})$ and slides were mounted in dithioerythritol $(4.4 \mathrm{mg} / \mathrm{ml}$; Sigma). The localization of nuclei (blue) of neurons (red) or glial and satellite cells (green) was recorded by laser-scan microscopy (Axiovert 100/LSM 500; Zeiss, Oberkochen, Germany) and images were stored electronically. The coverslips were carefully removed and the slides were further processed for DNA adduct staining.

Quantification of Pt-(GG) adducts in nuclear DNA by immunocytological assay. Immunofluorescence staining and measurement of specific DNA platination products were performed essentially as described by Liedert et al. (2006) with some modifications. Briefly, tissue sections were fixed in methanol and rehydrated in PBS. After partial denaturation, tissue sections were subjected to a two-step proteolytic digestion: (1) pepsin (DRG, $300 \mu \mathrm{g} / \mathrm{ml}$; spinal cord, $600 \mu \mathrm{g} / \mathrm{ml} ; 10 \mathrm{~min}, 37^{\circ} \mathrm{C}$ ) and (2) proteinase $\mathrm{K}\left(100 \mu \mathrm{g} / \mathrm{ml}, \mathrm{pH} 7.5 ; 10 \mathrm{~min}, 37^{\circ} \mathrm{C}\right)$. Pt-(GG) adducts in the nuclear DNA of individual cells were immunostained with the adductspecific monoclonal antibody R-C18 and were visualized by secondary "sandwich"-immunostaining as described previously (Liedert et al., 2006).

Immunofluorescence and DNA fluorescence signals were measured by digital image analysis and adduct levels in the nuclear DNA of individual cells were calculated as arbitrary fluorescence units (AFUs) by normalizing integrated antibody-derived fluorescence signals from $>400$ nuclei/cell type to the corresponding DNA content of the same cell. Statistical significance was assessed by means of ANOVA for repetitive AFU ( \pm SEM) measurements performed using SPSS (Chicago, IL) 9.1 software. A two-sided $p$ value of $<0.05$ was regarded as indicating statistical significance.

Statistical analysis. One-factorial ANOVAs were performed to compare mean body weights, mean amplitudes of $\mathrm{H}$ - and M-responses and mean sensory and motor conduction velocities in the groups of WT mice. One-factorial ANOVAs were used to compare the mean level of Pt-DNA adducts in neurons and glial cells of the spinal cord and neurons and 
A
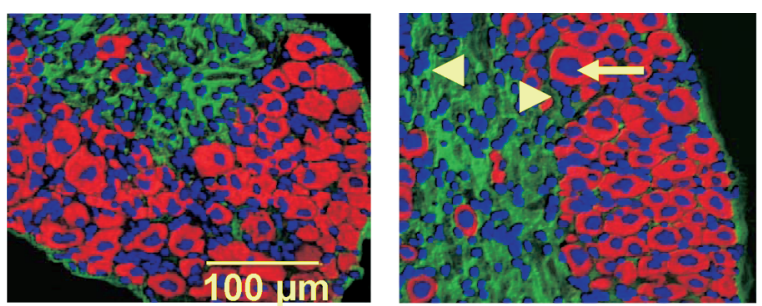

B
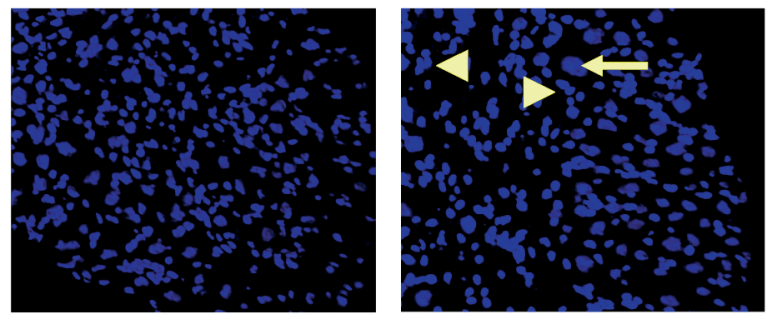

C

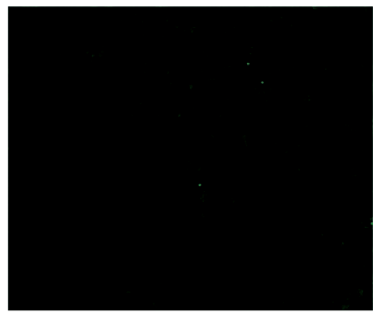

Untreated control

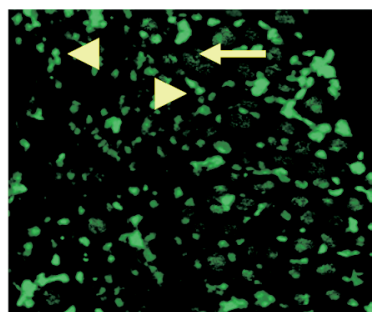

\section{$24 \mathrm{~h}$ after Cisplatin}

Figure 1. Visualization of Pt-(GG) adducts in the nuclear DNA of defined cell types of mouse dorsal root ganglia. $A, B$, DRGs were dissected from C57BL/6 mice (untreated or $24 \mathrm{~h}$ after i.p. application of $2 \mathrm{mg}$ cisplatin/ $\mathrm{kg}$ body weight) and cryosections were first stained for cell-typespecific markers (neurons: fluorescent Nissl stain, red, arrows; glial cells: CNPase, green, arrowheads) and counterstained for DNA with DAPI. C, After electronic recording of digital images, the sections were further processed for ICA analysis (see Materials and Methods) and immunostained for Pt-(GG) intrastrand cross-links in the nuclear DNA using monoclonal antibody R-C18 and green fluorescent secondary antibodies.

satellite cells of DRG in WT mice (factor "Dose": control vs 4, 8, 16, and 32 mg groups).

One-factorial ANOVAs were performed to compare the same variables between the groups of XPA mice. One-factorial ANOVAs were used to compare the mean level of Pt-DNA adducts in neurons and glial cells of the spinal cord and neurons and satellite cells of DRG in XPA mice (factor Dose: control vs 4 and $8 \mathrm{mg}$ groups).

Post hoc comparisons were performed using multiple $t$ tests with Bonferroni corrections. The level of significance was 0.05 .

\section{Results}

Visualization and measurement of cisplatin-DNA lesions in distinct cell types of the nervous system

To determine the level of DNA adducts in the nuclear DNA of mouse nervous tissue cells, we established a quantitative immunocytological assay (ICA) by combining cell-type-specific staining techniques and monoclonal antibody-based immunocytological measurement of DNA intrastrand cross-links. After injecting mice with cisplatin, cryosections of DRG and spinal cord (SC) were stained immunohistochemically for CNPase (a marker for glia and satellite cells; green) and by fluorescent Nissl stain for neurons (red), and were counterstained for nuclear DNA with DAPI (blue) (Fig. $1 A, B$ ). After recording, the digital images the slides were further processed for quantitative ICA analysis of Pt-(GG) cross-links in DNA using antibody R-C18 (Liedert et al., 2006) (Fig. 1C). Twenty-four hours after a single
A

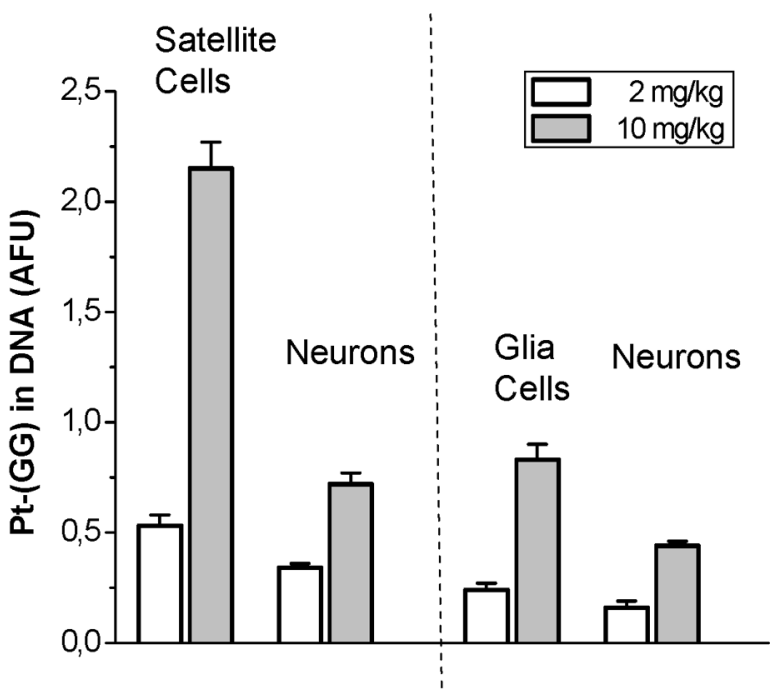

Dorsal Root Ganglia Spinal Cord

B

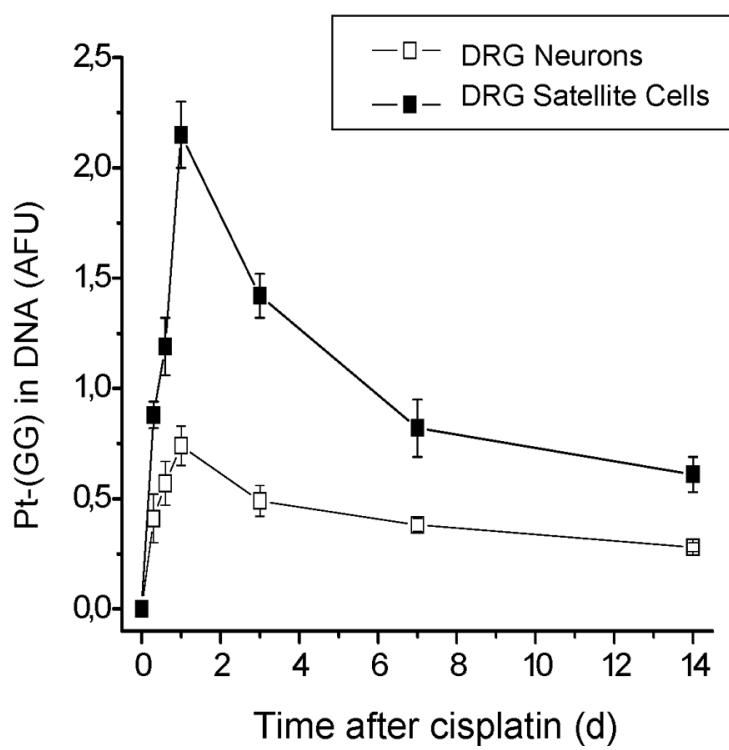

Figure 2. Levels of Pt-(GG) DNA adducts in different cells types of the peripheral and CNS of mice after a single dose of cisplatin (2 or $10 \mathrm{mg} / \mathrm{kg}$, i.p.). Cryosections from DRGs or spinal cord tissues were immunostained as in Figure 1 and integrated fluorescence signals from individual nuclei (blue, DNA; green, Pt-[GG]) (see Fig. 1) were measured by fluorescence microscopybased quantitative image analysis. Adduct-related signals were normalized for the actual DNA content of each cell and expressed as AFUs. Columns represent mean values ( \pm SEM) from each 200 cells. $A$, Comparison of peak adduct levels $24 \mathrm{~h}$ after drug injection. $\boldsymbol{B}$, Repair kinetics in DRG cells after a dose of $10 \mathrm{mg} / \mathrm{kg}$.

intraperitoneal injection of cisplatin ( $2 \mathrm{mg} / \mathrm{kg}$ body weight), PtDNA adducts were readily detectable in the nuclei of all investigated cell types (neurons and glial cells of the SC and neurons and satellite cells of the DRG). The measurements of integrated immunofluorescence signals from individual nuclei by quantitative image analysis revealed a distinct cell-type-specific pattern of adduct levels (Fig. 2). The accumulation of Pt-DNA lesions $24 \mathrm{~h}$ after cisplatin was significantly higher in DRG cells than in cells of the spinal cord inside the blood-brain barrier. Furthermore, the adduct levels were higher in satellite or glial cells than in neurons of the same anatomical structure. The formation of DNA platination products in DRG cells increased with the dose of cisplatin 


\section{Spinal cord}

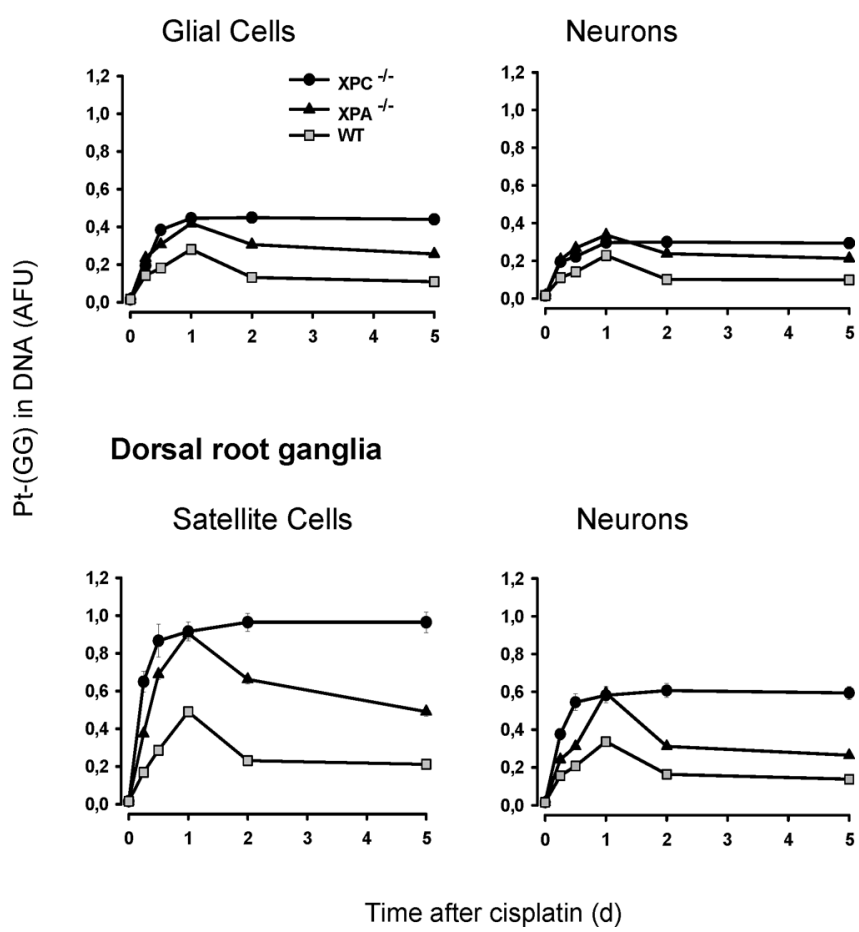

Figure 3. Formation and repair of Pt- $(\mathrm{GG})$ intrastrand cross-links in specific nervous tissue cells of mice after a single dose of cisplatin. C57BL wild-type mice and NER-deficient (XPA ${ }^{-1-}$ or XPC $\left.{ }^{-I}\right)$ mice were injected with cisplatin ( $2 \mathrm{mg} / \mathrm{kg}$, i.p.) and killed at different times after application. Levels of Pt-(GG) adducts in the nuclear DNA of specific cell types were measured by ICA analysis as in Figure 1 and 2. Data points represent mean values ( \pm SEM) of 200 evaluated cells randomly selected from tissue sections from two animals per time point and mouse strain.

and was approximately four times higher in satellite or glia cells and approximately two times higher in neurons when mice were injected with 10 instead of $2 \mathrm{mg} / \mathrm{kg}$ body weight (Fig. 2A).

Formation and repair of Pt-(GG) cross-links in neuronal tissue cells of mice proficient or deficient for nucleotide excision repair functions

Next, we determined the DNA adduct kinetics in cells of the peripheral nervous system and CNS of mice after acute exposure to cisplatin (Fig. 3). The Pt-(GG) levels increased slowly in all cell types and peaked $24 \mathrm{~h}$ after drug application. Within the next $24-48 \mathrm{~h}$, a major part of the lesions was removed from the nuclei of all four cell types by DNA repair, whereas the rest representing $30-50 \%$ of the initial burden remained unrepaired at a plateau level even $5 \mathrm{~d}$ after exposure. The persistence of cross-links at that time point was not caused by the exhaustion of cellular DNA repair systems because adduct kinetics at a higher dose of cisplatin $(10 \mathrm{mg} / \mathrm{kg}$ ) resulted in higher peak adduct formation (see above), but displayed nearly unaltered repair characteristics (Fig. $2 B)$.

To illuminate the contribution of a distinct repair mechanism in removing Pt-(GG) intrastrand cross-links from the genomic DNA of primary nervous cells, we analyzed, in parallel, mice with deficiencies in the NER pathway, namely, animals lacking either functional XPA or XPC protein (Fig. 3). As for C57BL/6 WT mice, the DNA adduct levels in cells of XPA ${ }^{-1-}$ mice peaked $24 \mathrm{~h}$ after a single dose of cisplatin $(2 \mathrm{mg} / \mathrm{kg})$, showing a similar celltype-specific adduct distribution with high values in satellite cells and neurons of the DRG, and comparatively lower levels in glial cells and neurons of the spinal cord. However, in XPA mice, the application of cisplatin induced up to twofold higher Pt-(GG) adduct levels compared with the corresponding cell type of identically treated WT mice, although the XPA-deficient cells were still competent to remove the intrastrand cross-links between 24 and $48 \mathrm{~h}$ at similar repair rates as their WT counterparts. Neuronal cells of XPA ${ }^{-1-}$ mice, too, left about half of the peak adduct burden unrepaired by day 5 after treatment, resulting in about two times higher plateau levels than in WT mice.

In XPC-deficient mice treated with the same dose of $2 \mathrm{mg}$ cisplatin $/ \mathrm{kg}$, the cell-type-specific adduct levels at $24 \mathrm{~h}$ displayed similarly high values as in XPA mice. However, in sharp contrast to the neuronal cells of WT and XPA mice, the cells of XPC mice were completely deprived in repairing Pt-(GG) adducts. Once formed, the lack of functional XPC protein resulted in a longterm persistence of the intrastrand cross-links in all four cell types of the nervous tissue (Fig. 3).

\section{Drug-induced DNA adducts accumulate in dorsal root ganglion and spinal cord cells during chronic treatment with cisplatin}

To mimic the clinical situation with repetitive treatment cycles and to prove whether the unrepaired portion of DNA intrastrand cross-links observed after a single application of cisplatin give rise to the accumulation of such lesions during chronic exposure, we injected WT mice with doses of $0.5 \mathrm{mg}$ cisplatin $/ \mathrm{kg}$ body weight twice per week. When the animals were killed after 2, 4, 8, 16, or 32 weeks of treatment, the ICA measurement indeed revealed a steady increase of Pt-(GG) DNA adduct levels with the cumulative dose in all four cell types (Fig. 4A). Similar to the situation after acute exposure (see above), cells in the dorsal root ganglia carried higher adduct burdens than cells of the spinal cord, and neurons were less affected than glia or satellite cells in the same anatomical location.

\section{Accumulation of Pt-(GG) adducts is higher in neuronal cells} of mice with dysfunctional nucleotide excision repair When NER-deficient XPA ${ }^{-1-}$ or XPC ${ }^{-1-}$ mice were exposed to the same repetitive application of cisplatin, increasing mortality was already observed at total doses $>10$ (XPA) or 6 (XPC) mg/kg body weight. The histopathological inspection of moribund animals revealed morphological alterations in the kidney. Therefore, XPC mice were excluded from this experiment and XPA mice were treated only up to a cumulative dose of $8 \mathrm{mg}$ cisplatin $/ \mathrm{kg}$ with no indications of renal failure. The cells of the central and peripheral nervous tissues carried, at each time point, significantly $(p<0.05)$ higher levels of Pt-(GG) adducts compared with the corresponding cell types in NER-proficient WT mice (Fig. $4 B$ ). This accelerated accumulation of cisplatin lesions was particularly pronounced at lower cumulative doses of 2 and 4 $\mathrm{mg} / \mathrm{kg}$, resulting in adduct burdens that were about twice as high as in WT mice.

Mice with reduced DNA repair capacity exhibit earlier onset of neurophysiological alterations during repetitive exposure to cisplatin

Next, we used this animal model to investigate the role of DNA adduct accumulation as a crucial initial event in cisplatin neurotoxicity finally leading to functional impairment. Mice were exposed to cisplatin as above and examined for alterations of electrophysiological parameters typically observed in drug-induced neuropathy. At various cumulative doses, groups of 10 animals were subjected to quantitative neurography. After proximal or 

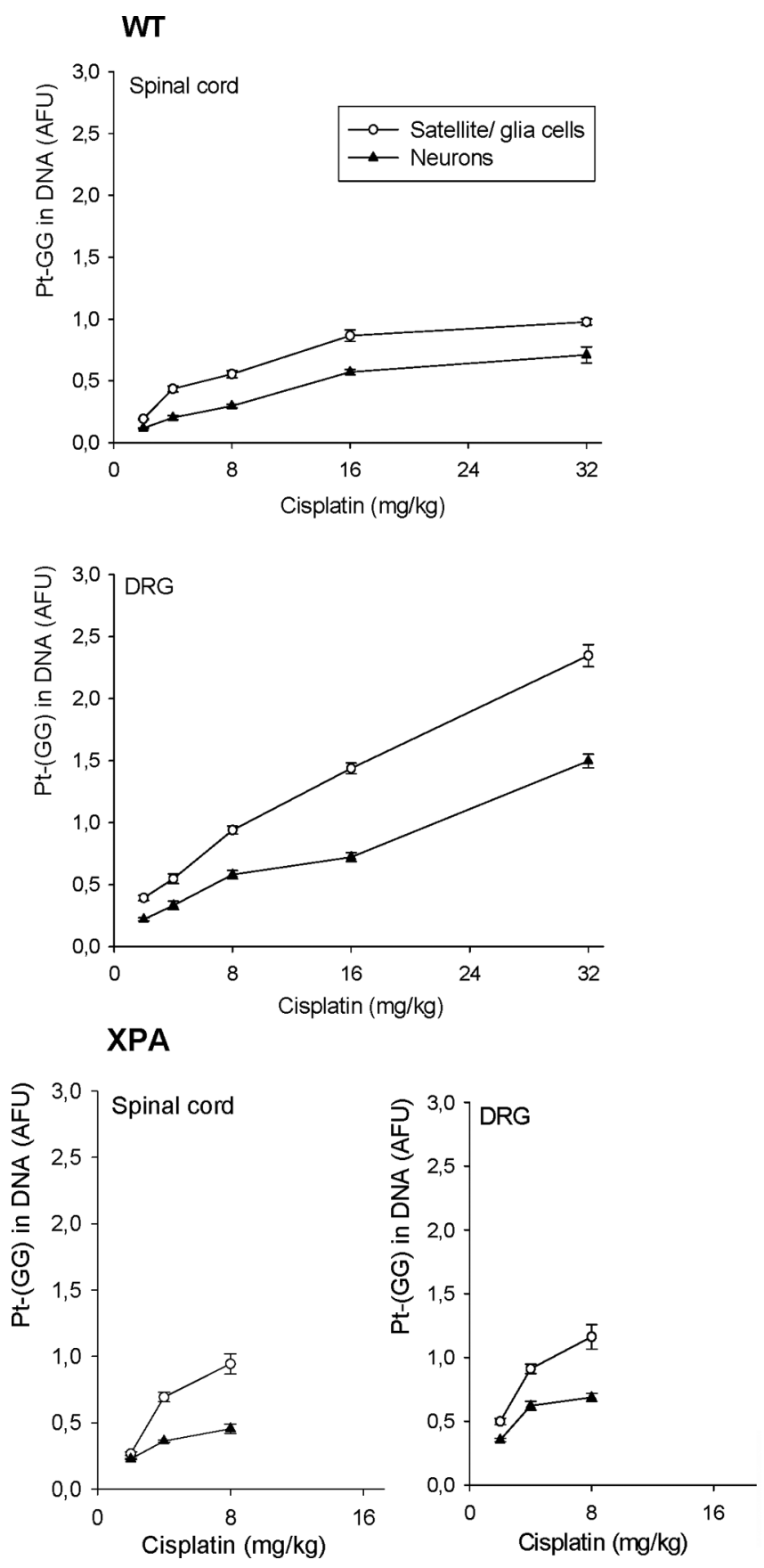

Figure 4. Accumulation of Pt-(GG) intrastrand cross-links in spinal cord and dorsal root ganglion cells of mice after repetitive applications of cisplatin. Syngenic $(57 \mathrm{BL} / 6$ wild-type or XPA-deficient mice were injected twice weekly with cisplatin $(0.5 \mathrm{mg} / \mathrm{kg}$, i.p.) and were killed at various cumulative doses of the drug (wild type, 2-32 mg/kg;XPA, 2-8 mg/kg; 10 animals per dose) $5 \mathrm{~d}$ after the last application. DNA adduct levels (mean \pm SEM) were measured by ICA analysis in randomly selected tissue sections of DRG or spinal cord samples from different mice as described in Figures 1 and 2 .

distal stimulation of the sciatic nerve in foot muscles, the MNCV and SNCV as well as the amplitudes of the $\mathrm{M}$ - and $\mathrm{H}$-responses were measured.

In WT mice, the amplitude of the H-responses steadily decreased with increasing cumulative doses (Table 1$)(\mathrm{df}=4 ; F=$ 5.9; $p<0.001$ ). A significant decrease of $\mathrm{H}$-response amplitudes was observed at total doses of $16 \mathrm{mg}$ of $(p=0.003)$ and $32 \mathrm{mg}$ cisplatin $(p=0.001)$. SNCV values in the sciatic nerve also changed with prolonged treatment $(\mathrm{df}=4 ; F=3.54 ; p=0.013)$ and a significant decrease was observed at a cumulative dose of 32 mg cisplatin ( $p=0.031)$. In contrast, no significant changes were observed for the M-responses and the MNCV compared with the untreated controls.

Electrophysiological examination of identically treated XPA mice revealed similar unaltered motor nerve values (MNCV and $\mathrm{M}$-amplitude) throughout the dose range ( $0-8 \mathrm{mg}$ cisplatin $/ \mathrm{kg})$. However, significant decreases of $\mathrm{H}$-responses and SNCV values were measurable already at a cumulative dose of $4 \mathrm{mg} / \mathrm{kg}$ with an additional reduction at $8 \mathrm{mg} / \mathrm{kg}$ (Table 1). At the latter dose a decrease of the H-responses by $61 \%$ and of the SNCV by $34 \%$ was observed in XPA mice compared with reductions of only $36 \%$ and $4 \%$ for the respective values in identically exposed WT mice. No significant discrepancies between both strains were observed for all four parameters when comparing the untreated control groups.

\section{Inverse correlation between the level of accumulated DNA} adducts and the magnitude of electrophysiological changes Because both syngenic mouse strains only differed in their ability to repair damaged DNA, the electrophysiological data strongly suggested that persisting cisplatin adducts represent the causative molecular trigger for the onset of PNP-like deficiencies. To further support this notion, we correlated the levels of unrepaired Pt-(GG) adducts in DRG neurons at a given cumulative dose of cisplatin to the corresponding values for SNCV and $\mathrm{H}$-amplitude. For both mouse strains, WT and XPA ${ }^{-1-}$, highly significant inverse correlations were found for the $\mathrm{H}$-responses (WT mice, Spearman's $r=-0.94, p=0.005$; XPA mice, $r=$ $-0.95, p=0.05$ ) as well as for the SNCV values (WT mice, $r=$ $-0.84, p=0.036$; XPA mice, $r=-0.96 ; p=0.045$ ), with a steep drop of both parameters at Pt-(GG) cross-link levels between 0.4 and 0.8 AFU values (Fig. 5). A similarly stringent inverse correlation was found for the combined values from both mouse strains and for the persisting adduct levels in DRG satellite cells (H-amplitude, $r=-0.86, p=0.0015 ; \mathrm{SNCV}, r=-0.89 ; p=0.0006$ ).

\section{Discussion}

In this study, we attempted to identify the molecular pathogenic mechanisms that trigger the onset of polyneuropathy frequently observed in cancer patients after repetitive treatment with cisplatin. For this purpose, we have established a mouse model that allowed the concomitant analyses of PNP-related electrophysiological parameters as well as the formation and processing of structurally defined DNA reaction product of cisplatin in individual cells of neuronal tissues.

Until now, the measurement of platinum concentrations in tissue samples or in isolated DNA was based predominantly on spectroscopic methods (Reed et al., 1987; McDonald et al., 2005). Only one report described the immunostaining of DNA platination products in DRG cells of cisplatin-treated rats by a polyclonal antiserum (Meijer et al., 1999). This method, however, did not allow quantitative measurement and was not suited to identify structurally defined DNA lesions. Here, we used an adduct-specific monoclonal antibody in combination with digital image analysis (ICA method) to visualize and quantify low levels of distinct DNA platination products in the nuclei of individual cells.

When analyzing cryosections of nervous tissues from cisplatin-treated mice with Mab R-C18, we found that the formation of the main intrastrand cross-link, Pt-GG, was about twofold higher in peripheral DRG neurons and satellite cells than in the corresponding cells of the spinal cord (Fig. 2). Most likely, this is because of the protective role of the blood-brain barrier, which 
Table 1. Electrophysiological changes in the course of repetitive exposure of NER-proficient (WT) and NER-deficient (XPA) mice to cisplatin

\begin{tabular}{|c|c|c|c|c|c|c|c|c|c|c|}
\hline Mouse strain & WT & $\mathrm{XPA}$ & WT & XPA & WT & XPA & WT & XPA & WT & WT \\
\hline Cumulative dose of cisplatin & Control & Control & $2 \mathrm{mg} / \mathrm{kg}$ & $2 \mathrm{mg} / \mathrm{kg}$ & $4 \mathrm{mg} / \mathrm{kg}$ & $4 \mathrm{mg} / \mathrm{kg}$ & $8 \mathrm{mg} / \mathrm{kg}$ & $8 \mathrm{mg} / \mathrm{kg}$ & $16 \mathrm{mg} / \mathrm{kg}$ & $32 \mathrm{mg} / \mathrm{kg}$ \\
\hline $\operatorname{MNCV}(\mathrm{m} / \mathrm{s})$ & $64.2 \pm 5.5$ & $67.9 \pm 2.5$ & $61.5 \pm 2.5$ & $57.0 \pm 2.6$ & $74.3 \pm 4.9$ & $60.2 \pm 3.9$ & $63.1 \pm 3.2$ & $67.1 \pm 4.1$ & $58.7 \pm 3.7$ & $53.9 \pm 3.1$ \\
\hline $\mathrm{SNCV}(\mathrm{m} / \mathrm{s})$ & $43.5 \pm 3.5$ & $50.8 \pm 4.8$ & $45.9 \pm 1.2$ & $47.0 \pm 2.7$ & $46.0 \pm 3.7$ & $37.1 \pm 4.1$ & $41.8 \pm 2.9$ & $33.4 \pm 3.3$ & $31.6 \pm 4.3$ & $30.7 \pm 4.1$ \\
\hline M-amplitude (mV) & $5.3 \pm 0.5$ & $5.9 \pm 0.5$ & $5.4 \pm 0.2$ & $5.9 \pm 2.6$ & $4.4 \pm 0.3$ & $4.8 \pm 0.3$ & $4.6 \pm 0.7$ & $4.1 \pm 0.7$ & $4.0 \pm 0.4$ & $4.3 \pm 0.3$ \\
\hline H-amplitude (mV) & $1.5 \pm 0.2$ & $1.7 \pm 0.1$ & $1.7 \pm 0.1$ & $1.7 \pm 0.7$ & $1.2 \pm 0.1$ & $1.0 \pm 0.1$ & $0.9 \pm 0.1$ & $0.8 \pm 0.1$ & $0.8 \pm 0.1$ & $0.7 \pm 0.1$ \\
\hline
\end{tabular}

Means ( \pm SEM) from 10 animals. Values showing significant differences to untreated controls are bold.

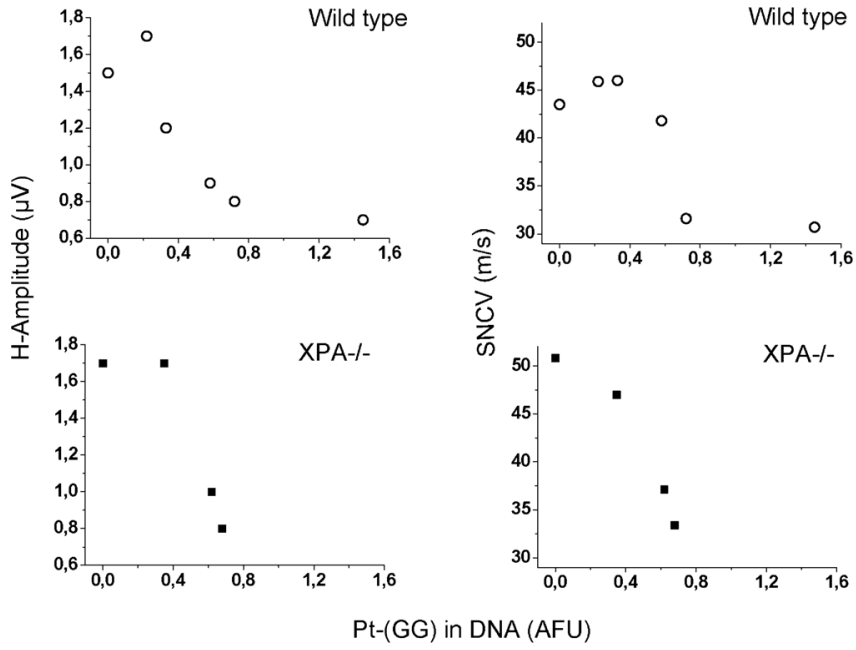

Figure 5. Levels of unrepaired Pt-(GG) adducts in DRG cells are significantly correlated with the magnitude of electrophysiological alterations. Both the amplitudes of the $\mathrm{H}$-responses and the SNCV measured in NER-proficient (WT) or -deficient (XPA) mice after repetitive applications of cisplatin display significant negative correlations to the proportion of persisting DNA intrastrand cross-links in DRG neurons. Animals were injected twice weekly with cisplatin as described in Figure 4 and electrophysiological examination as well as the measurement of DNA adducts were performed at day 5 after the last application. The inverse correlations were highly significant $(p<0.05)$ for the $\mathrm{H}$-amplitudes as well as for the SNCV values independently from the repair phenotype of the animals.

shields brain and spinal cord cells from exposure after systemic application of cisplatin (Gregg et al., 1992; Screnci and McKeage, 1999). The comparatively high adduct burden in DRG cells as also reported for rats (McDonald et al., 2005) is in line with the pronounced sensory character of cisplatin-induced neuropathies in patients and with the impaired function of the sensory, but not of the motor, fibers in the tibial nerve as found in this study.

Inefficient DNA repair does not account for the higher adduct levels in satellite or glia cells because their adduct kinetics revealed similar repair profiles to the adjacent neurons (Fig. 3). Therefore, increased uptake (Safaei and Howell, 2005) and/or reduced efflux (Materna et al., 2005) by active transport of the drug may account for the higher DNA platination in glial cells. After cisplatin exposure of explanted dorsal ganglia from rats, Gill and Windebank (1998) demonstrated the induction of apoptosis in DRG neurons via translocation of the bax protein and activation of the mitochondrial pathway. These observations strongly suggest that DRG neurons may represent the target cells of cisplatin neurotoxicity, although the peak adduct formation is not as prominent as observed for distinct cells of other affected organs, like the tubular epithelia of the kidney or the marginal cells of the inner ear (Thomas et al., 2006).

Despite being repair-proficient for Pt-(GG) adducts, cells of the CNS and PNS were incapable to completely remove these lesions from their DNA. As shown for cells of other mouse tissues like liver or kidney (Liedert et al., 2006), about one third of the initially formed intrastrand cross-links persisted unrepaired, even $5 \mathrm{~d}$ after drug application (Fig. 3). The refractory character of this portion is most likely attributable to poor accessibility for repair mechanisms and not to their exhaustion, because similarly shaped adduct curves were observed after fivefold higher doses of cisplatin (10 mg instead of $2 \mathrm{mg} / \mathrm{kg}$ ) (Fig. $2 \mathrm{~A}$ ).

Previous observations in various experimental systems suggested a general downregulation in terminally differentiated neuronal cells of several DNA repair mechanisms, including global genomic NER (Nouspikel and Hanawalt, 2002). By measuring adduct kinetics in syngenic mice with a homozygous knock-out for either the XPA or the XPC protein, we could demonstrate that the NER pathway is definitely active in a number of differentiated nervous tissue cells of WT mice and that this function is essential for the removal of cisplatin intrastrand cross-links from the genomic DNA of those cells. Until now, however, it was unclear whether global genomic DNA repair or the preferential elimination of adducts from the transcribed strand of active genes plays the major role for preventing cisplatin-induced cytotoxicity in nondividing primary cells. The ICA method used in this study is not applicable to discriminate between the two NER subpathways at the level of individual cells. Comparison of the adduct kinetics revealed two unexpected results: (1) peak levels of Pt-(GG) adducts in DRG cells were nearly twofold higher in both knock-out strains compared with WT mice, indicating that NER functions already interfere with very early steps of cross-link formation, and (2) XPA-deficient cells, which have been shown to be completely deprived of repairing UV-induced dimers in DNA, were still capable to reduce the level of Pt-(GG) lesions by $\sim 30 \%$ within $4 \mathrm{~d}$. Although a previous study with siRNA-mediated downregulation of XPA in cisplatin-exposed cell lines suggested that recombination repair functions might be able to partly substitute for impaired NER (Cummings et al., 2006), such an activity has not yet been described in $\mathrm{G}_{0}$ cells. Therefore, the precise mechanism of the XPA-independent global genomic repair of cisplatin-DNA cross-links has to be further investigated.

Together, our observations suggest a new model of how reaction products of cisplatin with nuclear DNA are processed in mouse cells: both the rapidly formed monoadducts as well as the slowly occurring secondary (GG) intrastrand cross-links are efficiently recognized and repaired by intact NER machinery. After the loss of functional XPA or XPC proteins, guanine monoadducts are no longer removed, resulting in a significantly higher formation of Pt-(GG) lesions. Those cross-links can still be eliminated to some extend in cells lacking functional XPA, but are completely persistent in XPC-deficient cells. Interestingly, in the rare cases of adult patients with inherited XPC defects, this inability of the NER system was associated with significant neuronal cell loss in DRGs, most likely because of accumulated DNA damage from endogenous metabolites (Robbins et al., 2002).

Thus, we had available an animal model where after application of the same dose of cisplatin, the mouse strains differed in the amount of unrepaired intrastrand cross-links in peripheral and 
central nervous tissue cells. We used WT and XPA mice to investigate whether repetitive drug exposure resulted in strain-specific differential accumulation of DNA damage in those cells and whether this, in turn, correlated to alterations in electrophysiological parameters typically observed in cisplatin-induced neuropathy. Derogations in the sensory response of the tibial nerve were shown to be reliable indicators of cisplatin neurotoxicity in mice and rats (De Koning et al., 1987; Verdu et al., 1999).

During low-dose chronic exposure to cisplatin, we indeed found for both mouse strains a progressive accumulation of $\mathrm{Pt}$ (GG) lesions in DRG cells as well as a reduction of H-response amplitudes and a slowdown of the SNCV, indicating a progressive sensory neuropathy. Furthermore, we could show, separately for each mouse strain and in a cumulative data analysis, a significant correlation between the levels of persisting DNA adducts and the severity of functional sensory impairment (Table 1, Fig. 5). Although satellite cells accumulate significantly higher adduct levels than neurons after acute or chronic exposure, additional subcellular analyses in DRG tissue are needed to rule out whether cisplatin induces predominantly a neuropathy rather than a Schwann cell pathology in mice.

Our results clearly demonstrate that suboptimal DNA repair in critical cells of the nervous system accelerates the accumulation of DNA cross-links during chronic application of cisplatin and may thus represent an important risk factor for druginduced neurotoxicity. Because humans vary up to 10 -fold in their individual DNA repair capacity of distinct cell types as shown (e.g., for blood lymphocytes) (Buschfort-Papewalis et al., 2002), skin fibroblasts (Bykov et al., 1999), or gut epithelium cells (Lees et al., 2006), such variations in the target cells of cisplatin neurotoxicity may account for the interindividual differences in latency and severity of PNP symptoms. Previous postmortem measurements of augmented tissue platinum content in patients with clinical signs of neuropathy further support this assumption (Gregg et al., 1992).

\section{References}

Berg RJ, Ruven HJ, Sands AT, de Gruijl FR, Mullenders LH (1998) Defective global genome repair in XPC mice is associated with skin cancer susceptibility but not with sensitivity to UVB induced erythema and edema. J Invest Dermatol 110:405-409.

Boulikas T, Vougiouka M (2003) Cisplatin and platinum drugs at the molecular level. Review. Oncol Rep 10:1663-1682.

Buschfort-Papewalis C, Moritz T, Liedert B, Thomale J (2002) Downregulation of DNA repair in human $\mathrm{CD} 34(+)$ progenitor cells corresponds to increased drug sensitivity and apoptotic response. Blood 100:845-853.

Bykov VJ, Sheehan JM, Hemminki K, Young AR (1999) In situ repair of cyclobutane pyrimidine dimers and $6-4$ photoproducts in human skin exposed to solar simulating radiation. J Invest Dermatol 112:326-331.

Cummings M, Higginbottom K, McGurk CJ, Wong OG, Koberle B, Oliver RT, Masters JR (2006) XPA versus ERCC1 as chemosensitising agents to cisplatin and mitomycin C in prostate cancer cells: role of ERCC1 in homologous recombination repair. Biochem Pharmacol 72:166-175.

De Koning P, Neijt JP, Jennekens FG, Gispen WH (1987) Evaluation of cis-diamminedichloroplatinum (II) (cisplatin) neurotoxicity in rats. Toxicol Appl Pharmacol 89:81-87.

Furuta T, Ueda T, Aune G, Sarasin A, Kraemer KH, Pommier Y (2002) Transcription-coupled nucleotide excision repair as a determinant of cisplatin sensitivity of human cells. Cancer Res 62:4899-4902.

Gill JS, Windebank AJ (1998) Cisplatin-induced apoptosis in rat dorsal root ganglion neurons is associated with attempted entry into the cell cycle. J Clin Invest 101:2842-2850.

Gregg RW, Molepo JM, Monpetit VJ, Mikael NZ, Redmond D, Gadia M, Stewart DJ (1992) Cisplatin neurotoxicity: the relationship between dosage, time, and platinum concentration in neurologic tissues, and morphologic evidence of toxicity. J Clin Oncol 10:795-803.
Hansen SW, Helweg-Larsen S, Trojaborg W (1989) Long-term neurotoxicity in patients treated with cisplatin, vinblastine, and bleomycin for metastatic germ cell cancer. J Clin Oncol 7:1457-1461.

Krarup-Hansen A, Fugleholm K, Helweg-Larsen S, Hauge EN, Schmalbruch H, Trojaborg W, Krarup C (1993) Examination of distal involvement in cisplatin-induced neuropathy in man. An electrophysiological and histological study with particular reference to touch receptor function. Brain 116:1017-1041.

Lees NP, Harrison KL, Hall CN, Margison GP, Povey AC (2007) Human colorectal mucosal O6-alkylguanine DNA-alkyltransferase activity and DNA-N7-methylguanine levels in colorectal adenoma cases and matched referents. Gut 56:380-384.

Liedert B, Pluim D, Schellens J, Thomale J (2006) Adduct-specific monoclonal antibodies for the measurement of cisplatin-induced DNA lesions in individual cell nuclei. Nucleic Acids Res 34:e47.

LoMonaco M, Milone M, Batocchi AP, Padua L, Restuccia D, Tonali P (1992) Cisplatin neuropathy: clinical course and neurophysiological findings. J Neurol 239:199-204.

Materna V, Liedert B, Thomale J, Lage H (2005) Protection of platinumDNA adduct formation and reversal of cisplatin resistance by anti-MRP2 hammerhead ribozymes in human cancer cells. Int J Cancer 115:393-402.

McDonald ES, Windebank AJ (2002) Cisplatin-induced apoptosis of DRG neurons involves bax redistribution and cytochrome $\mathrm{c}$ release but not fas receptor signaling. Neurobiol Dis 9:220-233.

McDonald ES, Randon KR, Knight A, Windebank AJ (2005) Cisplatin preferentially binds to DNA in dorsal root ganglion neurons in vitro and in vivo: a potential mechanism for neurotoxicity. Neurobiol Dis 18:305-313.

Meijer C, de Vries EG, Marmiroli P, Tredici G, Frattola L, Cavaletti G (1999) Cisplatin-induced DNA-platination in experimental dorsal root ganglia neuronopathy. Neurotoxicology 20:883-887.

Mollman JE (1990) Cisplatin neurotoxicity. N Engl J Med 322:126-127.

Nakane H, Takeuchi S, Yuba S, Saijo M, Nakatsu Y, Murai H, Nakatsuru Y, Ishikawa T, Hirota S, Kitamura Y, Kato Y, Tsunoda Y, Miyauchi H, Horio T, Tokunaga T, Matsunaga T, Nikaido O, Nishimune Y, Okada Y, Tanaka K (1995) High incidence of ultraviolet-B-or chemical-carcinogeninduced skin tumours in mice lacking the xeroderma pigmentosum group A gene. Nature 377:165-168.

Nouspikel T, Hanawalt PC (2002) DNA repair in terminally differentiated cells. DNA Repair (Amst) 1:59-75.

Reed E, Litterst CL, Thill CC, Yuspa SH, Poirier MC (1987) cisDiamminedichloroplatinum (II)-DNA adduct formation in renal, gonadal, and tumor tissues of male and female rats. Cancer Res 47:718 -722.

Robbins JH, Kraemer KH, Merchant SN, Brumback RA (2002) Adult-onset xeroderma pigmentosum neurological disease-observations in an autopsy case. Clin Neuropathol 21:18-23.

Safaei R, Howell SB (2005) Copper transporters regulate the cellular pharmacology and sensitivity to Pt drugs. Crit Rev Oncol Hematol 53:13-23.

Screnci D, McKeage MJ (1999) Platinum neurotoxicity: clinical profiles, experimental models and neuroprotective approaches. J Inorg Biochem 77:105-110.

Siddik ZH (2003) Cisplatin: mode of cytotoxic action and molecular basis of resistance. Oncogene 22:7265-7279.

Ta LE, Espeset L, Podratz J, Windebank AJ (2006) Neurotoxicity of oxaliplatin and cisplatin for dorsal root ganglion neurons correlates with platinum-DNA binding. Neurotoxicology 27:992-1002.

Thomas JP, Lautermann J, Liedert B, Seiler F, Thomale J (2006) High accumulation of platinum-DNA adducts in strial marginal cells of the cochlea is an early event in cisplatin but not carboplatin ototoxicity. Mol Pharmacol 70:23-29.

Thompson SW, Davis LE, Kornfeld M, Hilgers RD, Standefer JC (1984) Cisplatin neuropathy. Clinical, electrophysiologic, morphologic, and toxicologic studies. Cancer 54:1269-1275.

Verdu E, Vilches JJ, Rodriguez FJ, Ceballos D, Valero A, Navarro X (1999) Physiological and immunohistochemical characterization of cisplatininduced neuropathy in mice. Muscle Nerve 22:329-340.

Welsh C, Day R, McGurk C, Masters JR, Wood RD, Koberle B (2004) Reduced levels of XPA, ERCC1 and XPF DNA repair proteins in testis tumor cell lines. Int J Cancer 110:352-361.

Wood RD, Araujo SJ, Ariza RR, Batty DP, Biggerstaff M, Evans E, Gaillard PH, Gunz D, Koberle B, Kuraoka I, Moggs JG, Sandall JK, Shivji MK (2000) DNA damage recognition and nucleotide excision repair in mammalian cells. Cold Spring Harb Symp Quant Biol 65:173-182. 